\title{
(6) OPEN ACCESS \\ Listen and learn: engaging young people, their families and schools in early intervention research
}

\author{
Charlotte Connor, ${ }^{1,2}$ on behalf of Collaboration for Leadership in Applied Health \\ Research and Care West Midlands (CLAHRC-WM) Youth Mental Health
}

\begin{abstract}
'Research Lead Youth Mental Health Theme Collaboration for Leadership in Applied Health Research and Care West Midlands (CLAHRC-WM), University of Warwick, Coventry, UK

2Research and Innovation Centre for Mental Health, The Barberry Centre, Birmingham, UK
\end{abstract}

\section{Correspondence to}

Dr Charlotte Connor, Research and Innovation Centre for Mental Health, The Barberry Centre, 25 Vincent Drive Birmingham B15 2FG, UK; charlotte.connor@warwick. ac.uk

Accepted 28 March 2017
CrossMark

To cite: Connor C.

Med Humanit

2017:43:124-129.

\section{ABSTRACT}

Recent policy guidelines highlight the importance of increasing the identification of young people at risk of developing mental health problems in order to prevent their transition to long-term problems, avoid crisis and remove the need for care through specialist mental health services or hospitalisation. Early awareness of the often insidious behavioural and cognitive changes associated with deteriorating mental well-being, however, is difficult, but it is vital if young people, their families and those who work with them are to be fully equipped with the skills to aid early help-seeking. Our early intervention research continues to highlight the necessity of engaging with and listening to the voices of young people, families and those who work with children and young people, in developing greater understanding of why some young people may be more at risk in terms of their mental health, and to provide children and young people with the best mental health support we can. Collaborative working with young people, their families and those who work with them has been an essential dimension of our youth mental health research in Birmingham, UK, enabling us to listen to the personal narratives of those with lived experience and to work alongside them. This paper highlights some of our key studies and how we have endeavoured to make intra-agency working successful at each stage of the research process through increasing use of digital and youth-informed resources to engage young people: a methodology which continues to inform, guide and develop our early intervention research and implementation.

\section{INTRODUCTION}

Intervening during the early stages of a young person's mental health problems may help prevent transition to long-term issues, avoid crisis and remove the need for care through specialist mental health services or hospitalisation. ${ }^{1}$ The work of the CLAHRC-WM (Collaboration for Leadership in Applied Health Research and Care, West Midlands) Youth Mental Health theme focuses specifically on early identification and intervention for young people with regard to their mental health. The Five-Year Forward View (2014), published by NHS England, emphasised the need to design and deliver new models of healthcare to better meet the needs of patients. In particular, the report highlighted the necessity for greater engagement with patients, carers and communities in order to improve care pathways, promote well-being and prevent ill health. ${ }^{2}$ This paper highlights some of the key research of the CLAHRC-WM team and illustrates the importance of greater engagement and consultation with young people with regard to their mental health.

\section{TALKING ABOUT FIRST-EPISODE PSYCHOSIS}

Understanding who may be at risk of developing mental health problems and providing the opportunity to intervene before things reach crisis point is, however, problematic. Young people, their relatives or carers and those who work with young people may experience difficulties in recognising the need for help and also struggle with how, when and where they can access mental health support. This situation can leave many young people in a highly vulnerable state, experiencing untreated mental health difficulties for inordinate amounts of time prior to reaching specialist treatment.

This challenging state of affairs was highlighted in our recent exploration of the care pathways of young people with first-episode psychosis (FEP), specifically focusing on those who experienced a long time between the onset of their psychotic symptoms and accessing specialist treatment (referred to as DUP (duration of untreated psychosis)), ${ }^{3}$ which has significant consequences for ongoing mental health and treatment outcomes. ${ }^{45}$

Early intervention teams (EIT) are specialised services for young people between the ages of 14 and 35 who are experiencing the symptoms of FEP. EIT are accessed via referral from primary care, for example, a general practitioner (GP), or from within secondary mental healthcare teams, such as a community mental health team (CMHT) or child and adolescent mental health services (CAMHS). These teams offer multidisciplinary, multiagency assessment, treatment and care for those with a wide range of mental health problems.

Our exploration of the care pathways of a group of young people who had been accepted to an EIT in Birmingham, but who had experienced a long DUP ( $>6$ months) ${ }^{3}$ revealed that long DUP was often due to young people and their families not seeking help for symptoms during the early stages of their illness. This was typically due to poor knowledge and awareness of the early warning signs of psychosis and stigmatic attitudes regarding mental health; knowledge and awareness often informed by negative media representation of mental ill health; and adverse familial experiences of mental health service provision. However, even when early help was sought, many young people went on to experience further delays within mental health services themselves, most commonly with delayed referrals from secondary CMHTs to specialist EIT due to under-recognition of psychotic symptoms by staff, poor disclosure or disengagement from services. 
This work described analysed care pathway documents and medical notes to paint the picture of a typical care pathway of someone with long DUP. While informative, this methodology was, nevertheless, restricted by the quality of accessible clinical documentation. In order to fully understand the subjective experience of a young person with FEP, we felt it essential to take time to engage with them and listen to their voices and the voices of those who care for them. The importance of engagement and consultation with young people regarding their welfare was highlighted by Article 12 of the United Nations Convention on the Rights of the Child almost 30 years ago. ${ }^{6}$ Signed by the UK in 1991, this document stressed the need to explore and consider the views of young people and children with regard to their well-being, to fully appreciate their needs and improve child and adolescent service provision. Following further recommendations from the Health Advisory Service in $1995,^{7}$ there has been a growing focus on the engagement of young people; 89 a survey by Young Minds, 'Stressed Out and Struggling' (SOS) Project (2006), concluded that young people 'want to be consulted and to be involved in the development of services, and commissioners will find that this involvement will help shape and guide improvement'. ${ }^{10}$ Yet, despite the WHO estimation that, globally, around $20 \%$ of young people will experience a mental health disorder in any given year, ${ }^{11}$ with one in ten requiring ongoing support or treatment for severe or persistent issues such as depression or anxiety, successful engagement and partnership working with young people to inform and shape youth mental health services is still a relatively new process and not standard practice. In light of such findings, we enhanced our psychosis care pathway analysis with an in-depth exploration of the personal narratives of young people who had experienced a very long DUP (>12 months) and their families. ${ }^{12}$ Fourteen complete 'family' dyads (a young person and their primary carer) consented to be interviewed about their experiences of emerging psychosis. All were interviewed individually in their own homes or another, previously agreed, setting. The stories they shared exposed the complexity of the help-seeking process, the tremendous difficulties they had faced in recognising the early warning signs of mental ill health, the stigma they experienced and the challenges they encountered knowing how, when and where to seek help. Inability for young people to fully comprehend the seriousness of their symptoms, to determine and source what help was needed, and to be able to communicate these needs to family members and mental health professionals, were common.

Being able to distinguish between the usual emotional unrest and turmoil typically associated with adolescence and what may be a serious mental health problem is notoriously difficult, and many carers told us how they had mistakenly interpreted the early signs of their relatives' illness as part of a 'teenage phase' which they hoped would pass and which had prevented them from early help-seeking. Even when help was sought from health professionals, however, tales of poor engagement with secondary mental health services had further impacted on the young person's swift and timely referral to EIT. While we acknowledge that the factors associated with poor help-seeking are often complex and idiosyncratic, our findings highlighted how the poisonous combination of delays in help-seeking alongside delays within secondary mental health services was responsible for long DUP in Birmingham.

\section{CHANGING THE CARE PATHWAYS OF THOSE WITH FEP}

In response to these significant findings, we were keen to explore the ways in which we might be able to reduce the DUP of young people with FEP, by directly targeting the delays identified by our interviews, improving understanding and awareness of the early warning signs of psychosis and ways to seek help, and developing better connections and engagement with mental health services. The successful TIPS study ('Tidlig oppdagelse og behandling av psykoser'-early detection and treatment of psychosis) ${ }^{13}$ used such an approach in an attempt to reduce DUP in Norway. Their trial introduced an early detection team for psychosis in a specified area of Norway but cleverly combined it with a youth-appropriate public health campaign aimed at improving awareness and knowledge of the early warning signs of psychosis, and was successful in reducing DUP in their context. Inspired by their results, we launched a proof-of-principle public health trial to explore whether adopting a similar approach to reducing DUP could be successful in our particular setting. ${ }^{14}$ Our trial had two clear aims, directly driven by our previous findings: (1) to reduce the delays within secondary mental health services, through the introduction of a direct referral youth-friendly mental health service for FEP, providing seamless transfer to EIT and removing the need for further assessment by secondary mental health services, and (2) to improve knowledge, awareness and help-seeking by young people and their families, through the design, development and implementation of a youth-friendly 'psychosis awareness' public health campaign which would provide a range of resources to increase the knowledge, awareness and engagement of the wider community with regard to youth mental health.

The new youth access pathway ('YouthSpace') was launched in July 2011. This service promoted within local GP surgeries in the locality and was embedded within two large CMHTs located in a specified area in the south of Birmingham and provided direct access to EIT, with prompt clinical assessment in a youth-appropriate setting for young people with FEP.

The central information and communication hub for the public health dimension of our trial, however, was our youth mental health website, http://www.youthspace.me. Carefully designed through consultation with young people, the website was our primary source of engagement with the community, providing young people, their families and those who work with them with youth-friendly, engaging, easily accessible and trusted online sources of mental health information, to improve their knowledge, promote discussion and raise awareness of FEP and, thereby, help improve help-seeking behaviour for psychosis. The public health campaign was informed using the 'Precede-Proceed' public health model framework ${ }^{15}$ and emphasised the use of youth-friendly images, text and content informed by ongoing consultation with our advisory board of young people with experience of mental health problems ('YouthBoard') and their families. Throughout the campaign, these groups provided great insight and expertise in the design and development of the website and campaign resources, including the use of the strapline 'Don't turn your back on the symptoms of psychosis' which featured on all campaign merchandise. The YouthBoard also produced a host of photographs and films about youth mental health and inspiring blogs which described their own experiences of psychosis and engaging with mental health services. These resources were available via the website and displayed at a variety of community events in the area. This extensive methodology enabled ongoing assessment of context and setting which evolved throughout the campaign to ensure a responsive, stratified 'knowledge-transfer' approach to our public health campaign.

While the website functioned as the central information and communication hub of the public health dimension of the 
campaign, we were very aware of the importance of embracing wider social media in engaging young people. Facebook and Twitter links, therefore, featured on all campaign materials (see figures 1 and 2) and gave us further opportunities to open a range of channels of communication with young people and their families, and the wider community, including schools and third sector organisations, to discuss youth mental health, learn about the benefits of early help-seeking and to 'spread the news' about the early warning signs of psychosis.

This targeted and youth-focused approach was effective in reducing DUP from median of 71 to 39 days. Delays within mental health services and help-seeking behaviour were also reduced. Our successful trial is the first UK study to reduce the DUP in young people with FEP. ${ }^{16}$

\section{SCHOOLSPACE}

While experiencing a serious mental health problem, such as psychosis, can result in lower educational attainment and increase the likelihood of participation in smoking, drug and alcohol abuse, and risky sexual behaviour, ${ }^{17}$ it can also have long-term consequences for a young person's mental well-being as they transition into adulthood. With half of lifetime mental health problems occurring before the age of $14,{ }^{18}$ the design and development of feasible, youth-appropriate and acceptable strategies to help improve recognition and avoid young people falling into crisis and requiring specialist mental health services is essential. ${ }^{19}$ Failure to do so may cost lives and also have serious economic consequences. ${ }^{20}$

Teachers and school nursing staff have great potential to be the instigators and communicators of early detection strategies to first identify and then work with vulnerable young people who may not have reached the threshold for diagnosis, or who are deemed at high risk. The Royal College of Nursing report on school nursing in $2012^{21}$ cites the government's public health white paper from 2004 'Choosing health: making health choices easier $^{22} 23$ which recognised the essential role that school nurses play in improving outcomes for children and young people and committed to providing schools with 'at least one full-time, year round, qualified school nurse for each secondary school and its cluster of primary schools'.

Research indicates that mental health awareness and education programmes, embedded within the school curriculum and

Figure 1 Campaign poster.

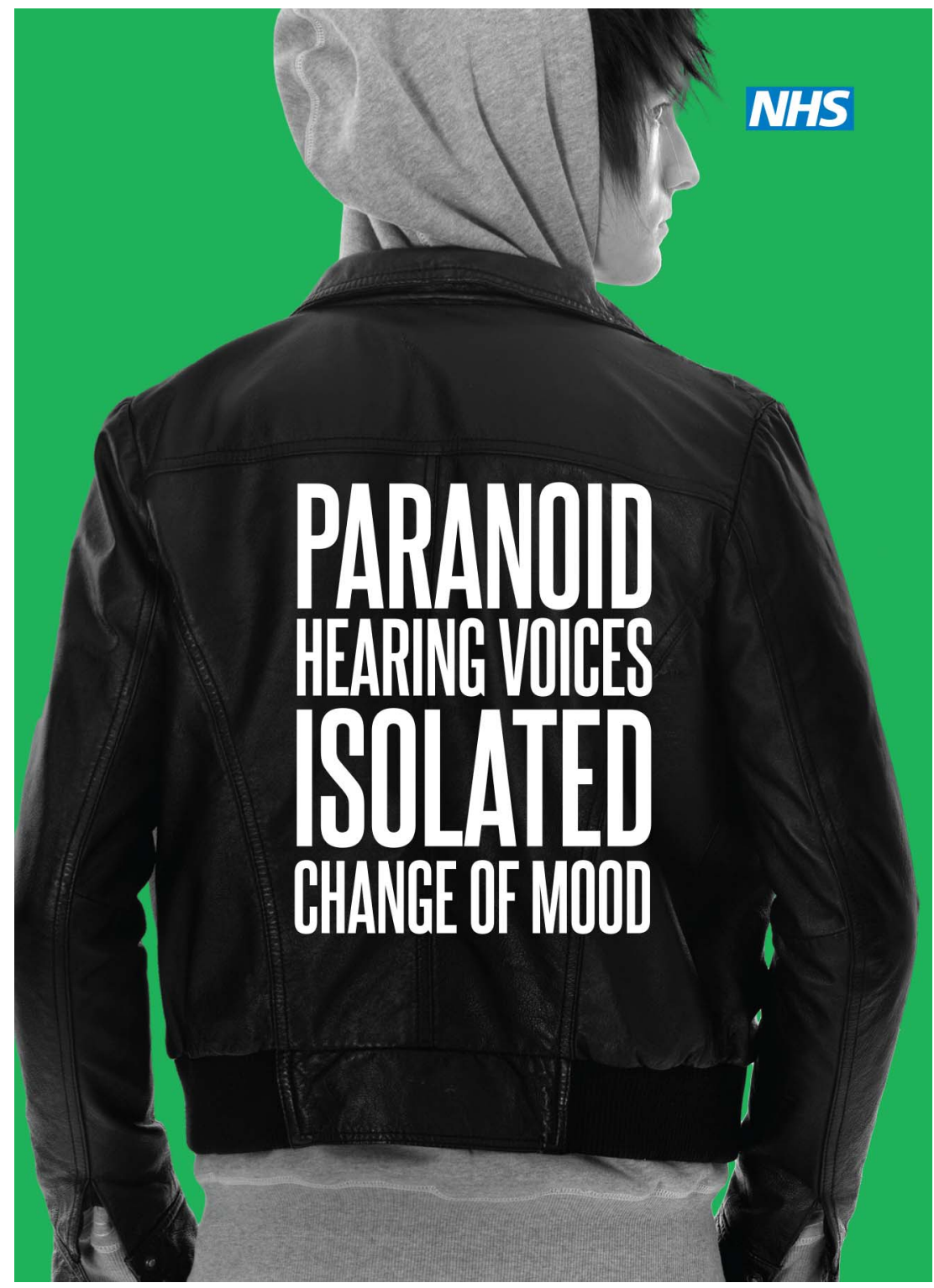




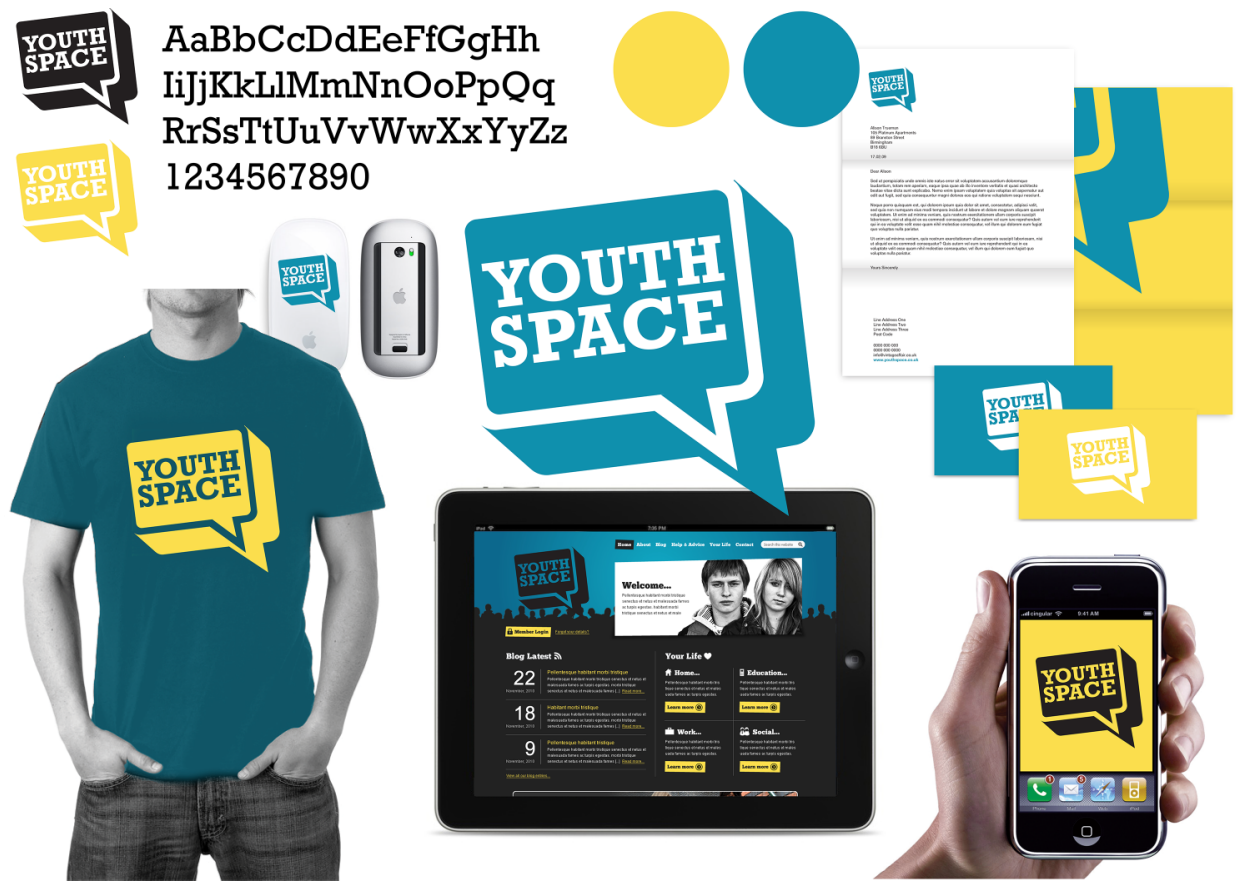

Figure 2 The YouthSpace branding on campaign materials.

delivered within schools can be extremely beneficial for young people, ${ }^{24}$ especially when using a 'whole school' approach whereby positive mental health and well-being is integrated into the ethos of the school. School nurses, however, are often overstretched; ${ }^{21}$ safeguarding and child protection work and national immunisation campaigns can take precedence over additional health-promoting activities. The role of educating young people about mental health, identifying and supporting those at risk, therefore, increasingly falls to teaching staff who may struggle to deliver consistent, youth-friendly mental health programmes, due to an increasingly packed curriculum with a primary focus on academic concerns and lack of expertise in the subject having received little or inadequate training. Recent reports from the Department of Health emphasise the importance of providing robust mental health training for teachers in order for them to offer appropriate education and support for their students. ${ }^{25} 26$ While many schools in the UK provide excellent programmes and support for their students, it is acknowledged that many do not, with mental health failing to be treated as a priority. Youth mental health is often only alluded to during initial teacher training in relation to safeguarding policies and is not necessarily included as part of continuing professional development, despite the increasing expectations put upon teachers to provide support for young people presenting with mental health issues. Acknowledgement of this shortfall has led to increased calls for child development and mental health to become essential components of the teacher training programme, enabling trainee teachers, in particular, to become proficient in supporting young people with their mental health.

It was through our contact with schools during the psychosis awareness public health trial that teachers revealed to us their concerns about their increasing role in supporting students with their mental health. Many questioned their capacity to access and deliver reliable youth-appropriate educational material and expressed further frustration at the difficulties faced when trying to secure professional help for a young person in their care. To explore these issues further, we conducted an online survey with teachers in Birmingham. ${ }^{27}$ One hundred and sixty secondary schools in the Birmingham Local Education Authority (LEA) were approached in November 2010. A total of 320 teaching staff responded to the survey over a 3 month period $(58 \%$ female and $39 \%$ male, of predominantly white British heritage (87\%); 72\% between the ages of 26 and 55 years). Teachers confirmed that, they do feel ill-prepared to support young people with their mental health, and that they themselves suffered from increasingly high levels of stress, dealing with their own mental health difficulties often preventing them from effectively supporting their students. Those who had experienced problems with their own mental health felt that lack of support and understanding of mental health from senior management teams had sometimes led them to hide their needs for fear of being regarded as unprofessional and unable to cope. Through this survey, it became evident to us that despite teachers being expected to support increasing numbers of young people with mental health problems such as depression, anxiety, eating disorders (EDs) and self-harm, they are themselves at risk and ill-prepared for the role.

These findings prompted the development of the 'SchoolSpace' network, a group of schools in Birmingham, UK, committed to working in collaboration with us in our early detection and intervention research. This collaboration aims to improve mental health education in schools, engage with young people and support teachers in their role as mental health advisors with a range of specially designed resources for themselves and their students to use. The network is also an opportunity for teaching staff and students to participate in our youth mental health research and play an integral part in the future design and development of evidence-based interventions, suitable for use within the school environment. 


\section{EDS-THE SCHOOLSPACE STUDY}

In order to develop evidence-based interventions for young people and to help prevent crisis, it is necessary to clearly understand the risk factors that are associated with the development of mental health difficulties. Approximately 80000 children and young people are estimated to suffer from depression and anxiety in Great Britain. ${ }^{28}{ }^{29}$ Such problems can often feature as early warning signs of other adolescent mental health problems, such as EDs and self-harm, ${ }^{30}{ }^{31}$ both of which can result in serious physical and mental consequences.

Anorexia nervosa (AN) is suggested to have risen threefold during the past 40 years ${ }^{32}$ and is predicted to rise further, and it is estimated that up to $40 \%$ adolescents have engaged in selfharm at some point in their lives, with the average age of onset 12-14 years. ${ }^{33}$ Early identification of young people at risk, however, remains a neglected area of research, ${ }^{34}$ and population studies to recognise early risk factors prior to full emergence of the illness are few. ${ }^{35}$ As with all mental health problems, paying greater attention to the risk factors before a clinical diagnosis of ED is reached, however, it may be possible to prevent many young people from requiring hospitalisation and long-term care. Primary risk factors for ED often focus on the physical characteristics of a young person such as perceived body size and weight. Emerging literature suggests, however, that nonweight factors, such as perfectionism, depression and anxiety, may be more helpful in determining those at risk and understanding the function that disordered eating behaviour may serve for individuals, such as emotional regulation. ${ }^{36}$ This was recently highlighted in qualitative explorations with young people. ${ }^{37}$ Studies in this area often focus on exploring young people's concepts of dieting and thinness, ${ }^{38}$ but a longitudinal cohort study in 1999 revealed that, while dieting was an important predictor of EDs in young women, it was psychiatric morbidity, such as pre-existing depression and anxiety, that increased their vulnerability during the early stages of their disordered eating behaviour and put them at an almost sevenfold increased risk of going on to develop a full-blown ED. ${ }^{35}$

Even just one discussion about eating behaviour, weight or shape concerns during a consultation with a young person in a primary care setting can be a strong predictor of the subsequent development of an ED. ${ }^{39}$ Indeed, in the 5 years preceding their ED diagnosis, girls with early onset $\mathrm{AN}$ have been observed to visit their GP more frequently to discuss issues involving eating, weight and shape, compared with girls with other mental health problems and healthy controls. ${ }^{37}$ Despite this knowledge, however, $50 \%$ of children under the age of 13 diagnosed with childhood onset ED are so unwell by the time they have accessed secondary care that they require immediate hospitalisation.

Universal interventions to prevent the development of ED in children and young people focus on providing all young people with useful strategies and knowledge, rather than specifically targeting those deemed 'at risk'. Universal interventions are typically implemented within a school setting and aim to raise general awareness of ED, exploring a wide range of attitudes and behaviours associated with disordered eating behaviour, improving media literacy and increasing their sense of advocacy in relation to body image and representation. While such interventions are often less stigmatising for young people and offer wide application, they are often generic, offering insufficient evidence to suggest they are effective for those deemed at risk. ${ }^{40}$ Targeted interventions produce the largest treatment effects, make the best use of limited resources and increase understanding of the wide range of risk and maintenance factors ${ }^{41}$ in the ED 'at-risk' population.
In an attempt to add to the literature regarding risk and resilience factors associated with the development of ED in adolescence, we recently conducted an online early detection ED study with the schools and students in our 'SchoolSpace' network via http://www.youthspace.me . Overall, 784 young people (male and female, aged 13-16 years) completed a survey at least once during the 24-month period (September 2014March 2016). The study was approved by the Research Ethics Committee at the University of Birmingham. Great care was taken in designing the survey to be attractive and meaningful to young people to help ensure high levels of engagement and participation given the potentially difficult subject matter. Students completed measures recording their eating behaviour, levels of depression and anxiety, incidents of self-harm, any difficulties with emotional regulation, levels of self-esteem, body esteem, adherence to food rules and dieting behaviour. Preliminary analysis of the data from the first two surveys has revealed that around $8 \%$ of young people reported some disordered eating behaviour. These were predominantly female and also reported greater levels of dieting behaviour, adherence to food rules, lower body esteem, difficulties with emotional regulation, greater levels of depression and anxiety and low self-esteem. Outcomes from this study will help us to develop a greater understanding of the risk and maintenance factors associated with the development of disordered eating behaviours during early adolescence and to work towards codesign and development of youth-informed screening tools and evidence-based interventions for use in schools in order to prevent ED. The importance of such evidence-based interventions and screening tools was recently highlighted by the Mental Health Commission of the think tank CentreForum stating that ' 65 per cent of schools do not use screening tools to differentiate between severity of mental health need (mild, moderate or severe). Yet, in schools where these tools are used, 85 per cent of head teachers reported they were effective'. ${ }^{42}$

\section{CONCLUSION}

An estimated 10\%-20\% of children and young people worldwide are affected by mental health issues, ${ }^{43}$ approximately $15 \%-25 \%$ of these psychiatric disorders believed to emerge during adolescence. ${ }^{44}$ Half of lifetime cases of psychiatric illness have had their onset by the age of 14 , with around threequarters by the age of $24 ;{ }^{18} 78 \%$ of cases $18-26$ years old with mental health problems have been diagnosed before the age of 18 , and $58 \%$ before age $15 .{ }^{45}$ Multiple prospective assessments, such as The Great Smoky Mountain Study ${ }^{18}$ and The Dunedin Study, ${ }^{46}$ have revealed the extent and cumulative rates of mental health disorders during adolescence, concluding that lifetime prevalence of such problems during adolescence is around $40 \%$. However, for those aged between the ages of 9 and 21 years, the figure has been argued to be more like $60 \%$, rising to $80 \%$ if diagnoses 'not otherwise specified' are taken into account, a diagnosis given to many young people presenting with low level or comorbid mental health problems which are unable to be captured using traditional DSM diagnoses. ${ }^{47}$

Many of the mental health problems experienced by young people will usually resolve themselves, without the need for specialist treatment or hospitalisation. It is the duration of an untreated episode which is likely to determine recurrence. ${ }^{48}$ This highlights the urgent need for greater understanding of the early warning signs of mental distress in young people. Listening to their personal experiences, engaging them in the design and development of preventative mental health strategies and encouraging them to become 
active participants in the research process are essential if we are to be able to provide truly effective early intervention.

Collaborators The Collaboration for Leadership in Applied Health Research and Care West Midlands (CLAHRC-WM) Youth Mental Health theme: Professor Max Birchwood (University of Warwick), Professor Nick Freemantle (University College London), Professor Swaran Singh (University of Warwick), Dr Paul Patterson (Forward Thinking Birmingham, Birmingham Children's Hospital), Mr Colin Palmer (University of Warwick), Mrs Sunita Channa (University of Warwick), Dr Anna Lavis (University of Birmingham) and Dr Newman Leung (Birmingham and Solihull Mental Health Foundation Trust).

Funding All research referred to in this paper were funded by the National Institute of Health Research as part of the CLAHRC-BBC (Collaboration for Leadership in Applied Health Research and Care-Birmingham and The Black Country) and CLAHRC-West Midlands. Charlotte Connor, Max Birchwood, Sunita Channa and Colin Palmer are all funded by CLAHRC West Midlands.

Disclaimer This paper presents independent research and the views expressed are those of the author(s) and not necessarily those of the NHS, the NIHR or the Department of Health.

\section{Competing interests None declared.}

Provenance and peer review Not commissioned; externally peer reviewed.

Open Access This is an Open Access article distributed in accordance with the Creative Commons Attribution Non Commercial (CC BY-NC 4.0) license, which permits others to distribute, remix, adapt, build upon this work non-commercially, and license their derivative works on different terms, provided the original work is properly cited and the use is non-commercial. See: http://creativecommons.org/ licenses/by-nc/4.0/

\section{REFERENCES}

1 Fryers T, Brugha T. Childhood determinants of adult psychiatric disorder. Clin Pract Epidemiol Ment Health 2013;9:1-50.

2 NHS England, Public Health England, Health Education England, Monitor, Care Quality Commission, NHS Trust Development Authority. Five Year Forward View. London: NHS England, Oct 2014. http://www.england.nhs.uk/wp-content/uploads/ 2014/10/5yfv-web.pdf

3 Birchwood M, Connor C, Lester $\mathrm{H}$, et al. Reducing duration of untreated psychosis: care pathways to early intervention in psychosis services. Br I Psychiatry 2013;203:58-64

4 Drake RJ, Haley CJ, Akhtar S, et al. Causes and consequences of duration of untreated psychosis in schizophrenia. Br J Psychiatry 2000;177:511-15.

5 Malla AK, Norman RM, Manchanda R, et al. One year outcome in first episode psychosis: influence of DUP and other predictors. Schizophr Res 2002;54:231-42.

6 The United Nations Convention on the Rights of the Child. London: UNICEF UK, 1989. http://www.unicef.org.uk/Documents/Publication-pdfs/UNCRC_ PRESS200910web.pdf (accessed 26 Apr 2016).

7 NHS Health Advisory Service. Together we stand-the commissioning, role and management of child and adolescent mental health services. London: HMSO, 1995.

8 Armstrong C, Hill M, Secker J. Listening to children. London: Mental Health Foundation, 1998.

9 Claveirole A. Listening to the voices in four Scottish adolescent mental health units: young people, their carers and the unit cultures. I Psychiatr Ment Health Nurs 2005; 11:253-60

10 Young Minds. Stressed Out and Struggling. A call to action: commissioning mental health services for 16-25 year olds. http://www.youngminds.org.uk/assets/0000/ 5391/SOS_YM_Call_to_Action.pdf (accessed 21 Oct 2016).

11 World Health Organisation. 10 Facts on Mental Health. Geneva: WHO. http://www. who.int/features/factfiles/mental_health/mental_health_facts/en/ (accessed 26 Apr 2016)

12 Connor C, Greenfield S, Lester H, et al. Seeking help for first-episode psychosis: a family narrative. Early Interv Psychiatry 2016;10:334-45.

13 Johannessen JO, McGlashan TH, Larsen TK, et al. Early detection strategies for untreated first-episode psychosis. Schizophr Res 2001;51:39-46.

14 Connor C, Birchwood M, Palmer C, et al. Don't turn your back on the symptoms of psychosis: a proof of principle quasi-experimental public health trial to reduce the duration of untreated psychosis in Birmingham UK. BMC Psychiatry 2013;13:67.

15 Green L, Kreuter M. Health program planning: an educational and ecological approach. 4th edn. New York, NY: McGraw-Hill, 2005.

16 Connor C, Birchwood M, Freemantle N, et al. Don't turn your back on the symptoms of psychosis: the results of a proof-of-principle, quasi-experimental intervention to reduce duration of untreated psychosis. BMC Psychiatry 2016;16:127.

17 Birmaher B, Ryan ND, Williamson DE, et al. Childhood and adolescent depression: a review of the past 10 years. Part I. I Am Acad Child Adolesc Psychiatry 1996:35:1427-39.

18 Kessler RC, Berglund P, Demler O, et al. Lifetime prevalence and age-of-onset distributions of DSM-IV disorders in the National Comorbidity Survey Replication. Arch Gen Psychiatry 2005;62:593-602.
19 Kelly $C M$, Jorm AF, Wright A. Improving mental health literacy as a strategy to facilitate early intervention for mental disorders. Med J Aust 2007;187:S26-30.

20 Knapp M, Snell T, Healey A, et al. How do child and adolescent mental health problems influence public sector costs? Inter-individual variations in a nationally representative British sample. J Child Psychol Psychiatry 2014;56:667-76.

21 Royal College of Nursing. The RCN's UK position on school nursing. https://www2. rcn.org.uk/_data/assets/pdf_file/0004/433282/School_nursing_position_ statement V5FINAL.pdf (accessed 21 October 2016).

22 Department of Health. Choosing health: making healthy choices easier. London: Stationery Office, 2004 (Cmnd 6374).

23 British Youth Council. Annual Review. 2012. http://www.byc.org.uk/wp-content/ uploads/2016/07/British-Youth-Council-Annual-Review-2011-2012.pdf (accessed 21 Oct 2016).

24 Barry MM, Clarke AM, Jenkins R, et al. A systematic review of the effectiveness of mental health promotion interventions for young people in low and middle income countries. BMC Public Health 2013;13:835.

25 Department for Education. Mental Health behaviour guidance to be offered to schools. 2014. https://www.gov.uk/government/news/mental-health-behaviourguidance-to-be-issued-to-schools (accessed 26 Apr 2016).

26 Department of Health. Future in Mind. Promoting, protecting and improving our children and young people's mental health and wellbeing. 2013. https://www.gov. uk/government/uploads/system/uploads/attachment_data/file/414024/Childrens_ Mental_Health.pdf (accessed 26 Apr 2016)

27 Palmer CJ, Connor C, Newton BJ, et al. Early intervention and identification strategies for young people at risk of developing mental health issues: working in partnership with schools in Birmingham, UK. Early Interv Psychiatry. Published Online First: 21 Aug 2015. doi: 10.1111/eip.12264.

28 Green H, McGinnity A, Meltzer $\mathrm{H}$, et al. Mental health of children and young people in Great Britain. London: Palgrave, 2004.

29 Hagell A. Social trends and mental health: introducing the main findings. London: Nuffield Foundation, 2013.

30 Kaye WH, Bulik CM, Thornton L, et al. Comorbidity of anxiety disorders with anorexia and bulimia nervosa. Am J Psychiatry 2004;161:2215-21.

31 Moran $\mathrm{P}$, Coffey $\mathrm{C}$, Romaniuk $\mathrm{H}$, et al. The natural history of self-harm from adolescence to young adulthood: a population-based cohort study. Lancet 2012;379:236-43

32 Halmi KA. Anorexia nervosa: an increasing problem in children and adolescents. Dialogues Clin Neurosci 2009;11:100-3.

33 Jacobson CM, Gould M. The epidemiology and phenomenology of non-suicidal self-injurious behavior among adolescents: a critical review of the literature. Arch Suicide Res 2007:11:129-47.

34 Treasure J, Claudino AM, Zucker N. Eating disorders. Lancet 2010;375:583-93.

35 Patton GC, Selzer R, Coffey C, et al. Onset of adolescent eating disorders: population based cohort study over 3 years. BMJ 1999;318:765-8.

36 Espeset E, Gulliksen $\mathrm{K}$, Nordbø R, et al. The link between negative emotions and eating disorder behaviour in patients with anorexia nervosa. Eur Eat Disord Rev 2012;20:451-60

37 Kyriacou O, Easter A, Tchanturia K. Comparing views of patients, parents, and clinicians on emotions in anorexia: a qualitative study. Health Psychol 2009;14:843-54.

38 Wick K, Brix C, Bormann B, et al. Real-world effectiveness of a German school-based intervention for primary prevention of anorexia nervosa in preadolescent girls. Prev Med 2011;52:152-8.

39 Lask B, Bryant-Waugh $R$, Wright $F$, et al. Family physician consultation patterns indicate high risk for early-onset anorexia nervosa. Int J Eat Disord 2005;38:269-72.

40 Pratt BM, Woolfenden SR. Interventions for preventing eating disorders in children and adolescents. Cochrane Database Syst Rev 2002:(2):CD002891.

41 Stice E. Risk and maintenance factors for eating pathology: a meta-analytic review. Psychol Bull 2002:128:825-48.

42 Taggart $H$, Lee $S$, McDonald $L$. The pursuit of happiness: a new ambition for our mental health. Perceptions of wellbeing and mental health in English secondary schools: a cross-sectional study. 2014. http://centreforum.org/live/wp-content/ uploads/2015/11/Headteacher-survey-cover.pdf (accessed 26 Apr 2016).

43 Kieling C, Baker-Henningham $\mathrm{H}$, Belfer $\mathrm{M}$, et al. Child and adolescent mental health worldwide: evidence for action. Lancet 2011;378:1515-25

44 Zachrisson HD, Rödje K, Mykletun A. Utilization of health services in relation to mental health problems in adolescents: a population based survey. BMC Publlic Health 2006:6:34

45 Kim-Cohen J, Caspi A, Moffitt TE, et al. Prior juvenile diagnoses in adults with mental disorder: developmental follow-back of a prospective-longitudinal cohort. Arch Gen Psychiatry 2003;60:709-17.

46 Copeland W, Shanahan L, Costello EJ, et al. Cumulative prevalence of psychiatric disorders by young adulthood: a prospective cohort analysis from the great smoky mountains study. J Am Acad Child Adolesc Psychiatry 2011;50:252-61.

47 Copeland WE, Shanahan L, Costello EJ, et al. Childhood and adolescent psychiatric disorders as predictors of young adult disorders. Arch Gen Psychiatry 2009;66:764-72.

48 Jaffee $\mathrm{S}$, Harrington $\mathrm{H}$, Cohen $\mathrm{P}$, et al. Cumulative prevalence of psychiatric disorder in youths. J Am Acad Child Adolesc Psychiatry 2005;44:406. 